\title{
Assessing the potential predictability of tropical cyclone activity in the Philippines on weekly timescales
}

\author{
Marcelino Q. Villafuerte II ${ }^{1, *}$, Tzu-Ting Lo ${ }^{2}$, Hsiao-Chung Tsai ${ }^{3}$, and Esperanza O. Cayanan ${ }^{1}$ \\ ${ }^{1}$ Department of Science and Technology - Philippine Atmospheric, Geophysical and Astronomical Services Administration, \\ Quezon City, Philippines \\ ${ }^{2}$ Central Weather Bureau, Taipei City, Taiwan \\ ${ }^{3}$ Tamkang University, New Taipei City, Taiwan
}

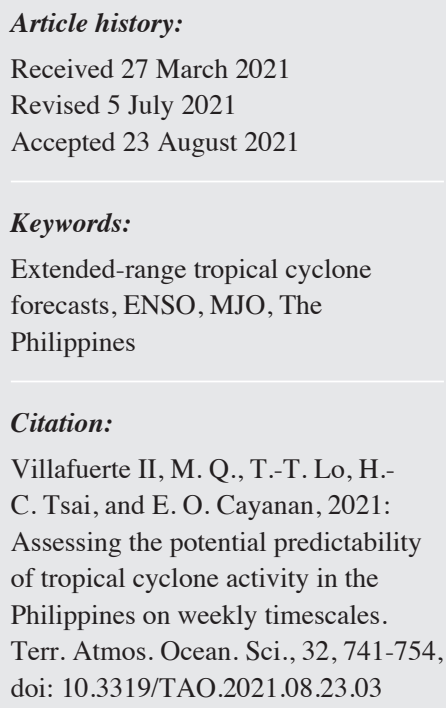

\begin{abstract}
This study investigates the potential predictability of tropical cyclone (TC) activity over the Philippine Area of Responsibility (PAR) on weekly timescales using the NCEP 16-day Global Ensemble Forecast System (NCEP-GEFS). An algorithm that uses information on selected dynamic and thermodynamic criteria was utilized to detect and track TC-like vortices (TCLV) from the 6-hourly NCEP-GEFS model runs covering a two-year period from 1 January to 31 December in 2015 and 2017. A $2 \times 2$ contingency table was used to summarize the event forecast relative to the observed TC occurrence and subsequent tracks over the PAR on weekly timescales. A forecast hit was declared if there is at least $50 \%$ overlap between the polygons created from the drawn circles with $500 \mathrm{~km}$ radius centered at the identified forecast TCLV center and the observed TC track. The hindcast period covering the evaluation of NCEP-GEFS indicate a hit-rate of 0.49 and 0.19 for the 1- and 2-week TC forecasts, respectively in the PAR. It is also revealed that the stronger the TC and the farther it developed to the eastern boundary of the PAR, which typically occur during El Niño (as in the 2015 case), the higher chance it could be forecasted one week ahead of time. Furthermore, better TC predictability in the PAR is achieved when the Madden-Julian Oscillation's active convection phase is located over Africa and the western Indian Ocean (Phase 1) for the Week-1 forecast period and over the Maritime Continent (Phase 5) for the Week-2 forecast period.
\end{abstract}

\section{INTRODUCTION}

Tropical cyclones (TCs) are among the major natural hazards that bring significant impacts to economic progress of the Philippines. On average, 19.4 TCs exist over the Philippine Area of Responsibility (PAR; enclosed by the dashed lines in Fig. 1) annually, of which almost half make landfall over the Philippines (Cinco et al. 2016). Those TCs that existed in the PAR, especially the landfalling ones, have been disastrous (e.g., Yumul et al. 2011; Cinco et al. 2016), but sometimes beneficial as well, because they bring substantial amount of freshwater necessary for agriculture and domestic use, among others (e.g., Bagtasa 2017). Considering both the positive and negative impacts of TCs in the Philippines, an effective TC forecasts would therefore be beneficial to

\footnotetext{
* Corresponding author

E-mail:mvillafuerte@pagasa.dost.gov.ph
}

the country and its inhabitants.

The El Niño-Southern Oscillation (ENSO) acts as a major source of TC predictability over the western North Pacific (WNP) on seasonal timescale (Chan et al. 1998; Camargo and Sobel 2005; Patricola et al. 2018). It has been demonstrated that TCs tend to become more intense and live longer over the WNP during El Niño events (Camargo and Sobel 2005). It has also been shown that TCs originate farther to the east of the Philippines over the WNP and tend to re-curve northeastward, reducing the number of TCs that make landfall over the country during El Niño events (Corporal-Lodangco et al. 2016).

For timescales shorter than a season (i.e., intra-seasonal scale), the Madden-Julian Oscillation (MJO) plays an important role in TC activity over the WNP, particularly in cyclogenesis (Liebmann et al. 1994). Also, more frequent TC 
activities are observed over the WNP during the active MJO phases than the suppressed ones (Sobel and Maloney 2000). Vitart (2009) further suggests that the accuracy of the models in predicting MJO affects the predicted TC frequency. In the following year, Belanger et al. (2010) affirmed that the skill of the European Center for Medium-range Weather Forecasts (ECMWF) monthly forecast systems is sensitive to the MJO phase and amplitude during the time of the model initialization for predicting TC activity.

In earlier decades until the early 2000s, TC forecasts (containing information on potential TC development and its possible movement path) are generally provided for lead times extending up to three days only (Elsberry 2014). Such forecasts were subsequently been extended to longer lead times as numerical weather prediction models began to improve. The pioneering study of Elsberry et al. (2010) has initially demonstrated the potential use of the ECMWF 32-day ensemble for WNP TC formation and tracks guidance on extended-range (5 - 30 days) timescales. Tsai et al. (2011) have also demonstrated the potential applicability of the National Centers for Environmental Prediction 16day Global Ensemble Forecast System (NCEP-GEFS) for extended-range TC forecast guidance over the WNP. Succeeding studies have further strengthened the promising future of TC forecasts provided at extended-range timescales, particularly for its operational application (e.g., Tsai and Elsberry 2013; Tsai et al. 2013; Elsberry et al. 2014; Vitart and Brown 2019).

As early as in 2008, a TC monitoring and prediction system for global TC activities has been developed at the Central Weather Bureau (CWB). The system is called the CWB TC Tracker, which employs the TC detection method described in Tsai et al. (2011). Such system has integrated an automatic downloading of the needed variables from the operational 21-member NCEP-GEFS model outputs where the TC detection and tracking algorithm is applied in near real-time. The TC tracking results are then archived and near real-time forecasts useful for extended-range TC prediction guidance are provided in an online platform at https://tctracker.cwb.gov.tw/. Starting from the 2020 TC season, the CWB TC Tracker has undergone a hardware upgrade to improve the forecast data availability. The forecast lead-time has also been extended to cover one-month forecasts. In addition to using the latest NCEP-GEFS version 12 (Zhou et al. 2017), the CWB TC Tracker also provides the TC tracking results obtained from multiple global ensemble models, such as the NCEP-CFSv2 (Climate Forecast System version 2) and the ECMWF monthly forecasting system.

The CWB TC Tracker outputs derived from the NCEP-GEFS have become one of the bases in providing (a)

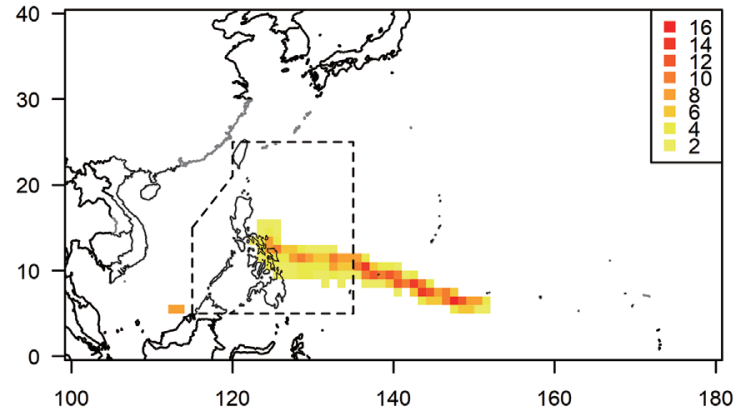

(c)

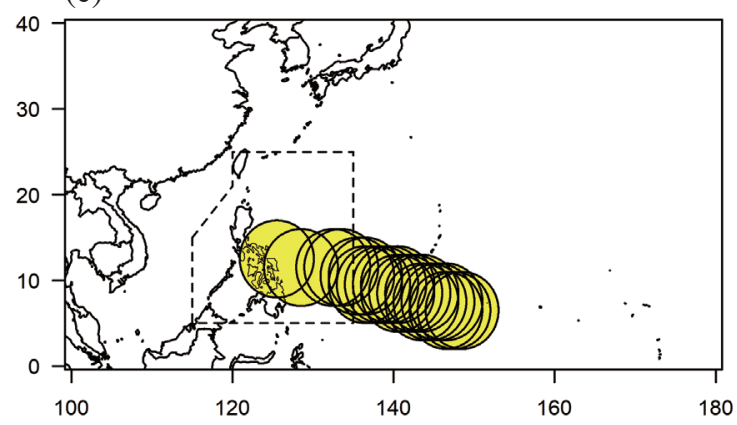

(b)

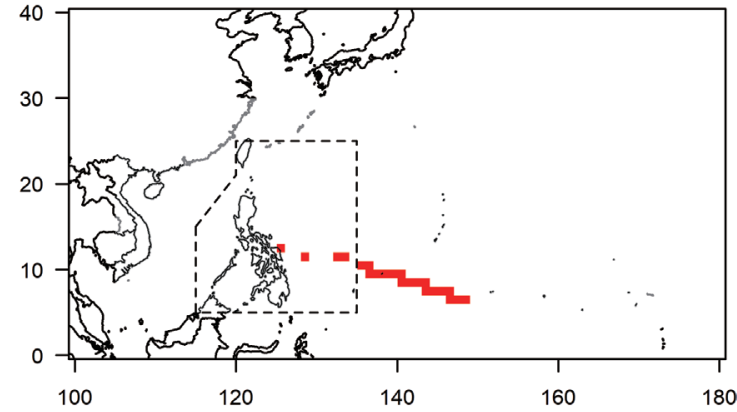

(d)

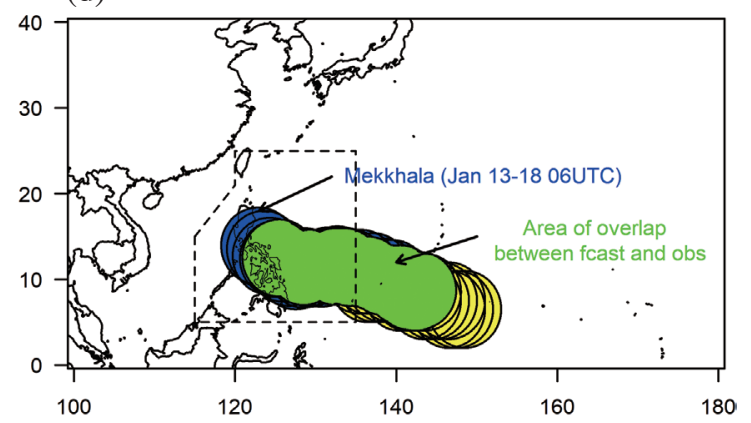

Fig. 1. Maps showing: (a) the number of ensemble members of the NCEP-GEFS individual model runs indicating TC activity in each grid cell covering a one week forecast period from its initialization time at 0600 UTC on 11 January 2015, (b) the grid cells in (a) that reached a threshold of at least 10 members (red-shaded areas), (c) forecast TC polygon (yellow-shaded area) created by connecting the circles with $500 \mathrm{~km}$ radius drawn from the center of each of the grid cells shown in (b), and (d) overlapping area (green-shaded region) between the observed (blue-shaded region) and forecast (yellow-shaded region) TC polygons; a forecast hit is declared if the area of overlap between the forecast and observed polygons is $\geq$ $50 \%$. An interactive near-real time version of (a) is accessible online at https://tctracker.cwb.gov.tw/. 
TC forecasts for lead times covering up to two weeks by the Climate Prediction Center (CPC) of the United States (see, https://www.cpc.ncep.noaa.gov/products/precip/CWlink/ghazards/). This has also been used internally within the Philippine Atmospheric, Geophysical and Astronomical Services Administration (PAGASA) in providing information on potential TC development and its possible movement path for Week-1 and Week-2 forecast periods (i.e., $00-168 \mathrm{~h}$ and $174-342 \mathrm{~h}$, respectively), but needs further refinements and better understanding to become fully operational. In support of these earlier initiatives, this study aims to evaluate the Week-1 and Week-2 TC forecasts of the CWB TC Tracker derived from the NCEP-GEFS over the PAR. The next section describes the datasets used and the methods employed to detect and track TCs, as well as the method of evaluating the TC forecasts. The results of evaluation, the characteristics of predictable and unpredictable TCs, and the potential influence of ENSO and MJO on TC predictability over the PAR are discussed in section 3. Then, the key findings and main conclusions are summarized in section 4 .

\section{DATA AND METHODS}

\subsection{TC Detection and Tracking}

TC-like vortices (TCLV) are detected and tracked from model outputs typically, using algorithms that look at the dynamic and thermodynamic characteristics of a system. Among the commonly used method for TC detection and tracking is the vortex tracker of the Geophysical Fluid Dynamics Laboratory (GFDL; Biswas et al. 2018), which offers operational application particularly for real-time monitoring and tracking of TCs. For detection and tracking of TCLVs from long-term climate model simulations, the TRACK software developed by Hodges (1995), has also been found useful in a number of studies (e.g., Manganello et al. 2012; Redmond et al. 2015; Villafuerte II et al. 2021). While there are a number of existing methods that can be used for detecting and tracking TCLVs from model outputs aside from the GFDL and TRACK, as mentioned earlier, the TC detection and tracking algorithm described in Tsai et al. (2011) has been used at the CWB for extended-range TC prediction.

Basically, the algorithm developed by Tsai et al.(2011) detects and tracks TCLVs from global ensemble model outputs based on the following criteria: $(i)$ the center of the system is identified at the minimum mean sea-level pressure within a $7^{\circ} \times 7^{\circ}$ latitude/longitude grid box; (ii) the 850 hPa relative vorticity $\zeta_{850} \geq 3.0 \times 10^{-5} \mathrm{~s}^{-1}$; (iii) the maximum 10 -m wind speed $\geq 10 \mathrm{~m} \mathrm{~s}^{-1}$; $(i v)$ the $300-\mathrm{hPa}$ air temperature anomaly $\left(T_{300}\right) \geq 0 \mathrm{~K}$; (v) $T_{300}-T_{850} \geq 0 \mathrm{~K}$; and ( $\left.v i\right)$ the difference in average eddy kinetic energy between the 850- and $300-h P a$ levels $\left(\mathrm{EKE}_{850}-\mathrm{EKE}_{300}\right) \geq 0$. An existence of a TCLV is declared if criteria $i-i v(i-v i)$ are met based on the
"Basic" ("All") criteria. The Basic and All criteria are further improved by combining the derived information with the fuzzy logic approach (Tsai et al. 2011), hereinafter referred to as the "Fuzzy-Basic" and "Fuzzy-All" criteria, respectively. As compared with the binary (yes/no) decisionmaking approaches, Tsai et al. (2011) applies user-specified smooth functions (so-called membership functions) and weightings to the TC detection criteria mentioned above to provide a combined-likelihood value for each grid box.

As mentioned in section 1, the TC tracking outputs of the CWB TC Tracker have been archived. However, due to limitations in the data storage and computational resources, the TC tracking results of 2015 and 2017 based on the NCEP-GEFS are the most complete archived datasets for detailed analyses. Hence, this study uses the available 6-hourly, 16-day NCEP-GEFS TC forecast outputs of the CWB TC Tracker covering the period from 0000 UTC January 1 to 1800 UTC December 31 in 2015 and 2017.

\subsection{Studied Domain and Method of Verification}

In this study, we focus our analyses of evaluation over the region covering the PAR (the area enclosed by the dashed lines in Fig. 1). The PAR is an irregularly shaped area enclosed by the following geographical points: $25^{\circ} \mathrm{N}$ $120^{\circ} \mathrm{E}, 20^{\circ} \mathrm{N} 120^{\circ} \mathrm{E}, 15^{\circ} \mathrm{N} 115^{\circ} \mathrm{E}, 5^{\circ} \mathrm{N} 115^{\circ} \mathrm{E}, 5^{\circ} \mathrm{N} 135^{\circ} \mathrm{E}$, and $25^{\circ} \mathrm{N} 135^{\circ} \mathrm{E}$; it is among the agreed areas of responsibility for providing storm warnings and shipping forecasts assigned to the Philippines (WMO 1966).

An existence of a TC is forecasted over the PAR during the Week-1 period if at least 10 (5 for the Week-2 forecast period) of the 21 ensemble members of the NCEPGEFS runs are indicating an existence of a TCLV based on the Fuzzy-All and Fuzzy-Basic criteria as described earlier. Doing so requires four steps as illustrated in Fig. 1. First, the TC detection is applied individually to the 21 ensemble members of the NCEP-GEFS and then collectively gathered to produce an information indicating how many of the ensemble members are indicating a presence of a TCLV in each of the grid cells (Fig. 1a). Next, the grid cells that reached a particular threshold [i.e., 10 (5) of the ensemble members for Week-1 (Week-2)] are retained (red-shaded regions in this example as shown in Fig. 1b). Then, polygons are created by connecting the circles with a radius of $500 \mathrm{~km}$ drawn from the center of the grid cells identified in the previous step (Fig. 1c), which is also done for the observed TCs, but the circles are drawn from the centers of the "best track" for observations. Finally, the area of overlap between the polygons drawn from the forecasts and observations are taken (green-shaded area in Fig. 1d). Here, the observed TCs are based on the 6-hourly TC center position of the best tracks archived by the Regional Specialized Meteorological Center-Tokyo in combination with the tracks of tropical depressions (i.e., TCs with maximum sustained 
wind speed $<17 \mathrm{~m} \mathrm{~s}^{-1}$ ) that did not reach tropical storm categories (TCs with maximum sustained wind speed ranging from 17 to $25 \mathrm{~m} \mathrm{~s}^{-1}$ ), but were identified and named locally by PAGASA. All the TCs that were observed over the PAR in 2015 and 2017, together with some relevant information about the TCs, are listed in Table 1.

The TC forecasts are classified into four types: (1) Hit, if a TC was observed and forecasted in almost the same location (obtaining at least $50 \%$ overlap between the polygons created from the observed and forecast TC positions as described earlier) covering the forecast time period (see, Fig. 1d for an example of an event obtaining a forecast hit); (2) Missed, if there was an observed TC but non-occurrence of TC was forecasted; (3) False Alarm, if a TC was forecasted to occur but nothing was observed; and (4) Correct Negative, if there was no TC that existed in the PAR and the same was forecasted during the period covered (i.e., Week-1 or Week-2). These are then summarized in a $2 \times 2$ contingency table (e.g., Wilks 2011) where four of the commonly used forecast verification metrics including hit rate (HR), equitable threat score (ETS), false alarm rate (FAR), and frequency bias $(\mathrm{FB})$ are derived. From the tabulated TC forecasts, HR, ETS, FAR, and FB are obtained as follows:

$H R=\frac{a}{a+c}$

$E T S=\frac{a-a_{r}}{a+b+c-a_{r}}$

$F A R=\frac{b}{b+d}$

$F B=\frac{a+b}{a+c}$

where: $a=$ total number of hits, $b=$ total number of false alarms, $c=$ total number of misses, $d=$ total number of correct negatives, and $a_{r}=\frac{(a+b)(a+c)}{\text { Total number of forecasts made }}$ which accounts for hits due to random chance (Wilks 2011).

The effects of MJO on predictability of TC activity over the PAR are investigated by employing composite analysis. The MJO index that we used in this study is based on the Australian Bureau of Meteorology as described by Wheeler and Hendon (2004), which can be downloaded online from http://www.bom.gov.au/climate/mjo/. The composites of large-scale atmospheric conditions used in the discussion were taken from the Japanese 55-year Reanalysis (JRA55; Kobayashi et al. 2015). Finally, the ENSO phase as described in this study is based on the CPC Oceanic Niño 3.4 index.

\section{RESULTS AND DISCUSSION}

\subsection{Comparison of TC Detection Criteria}

As mentioned in section 2.1, the CWB TC Tracker employs the Fuzzy-Basic and Fuzzy-All criteria for TC detection and tracking. The performance of Week-1 and Week2 TC forecasts over the PAR based on these two different methods applied to the NCEP-GEFS are first compared (Table 2). The overall HR obtained by the model is 0.60 (Fuzzy-Basic) and 0.49 (Fuzzy-All) for the Week-1 forecast during the analyzed period. These values, however, are reduced if the forecast hit due to random chance is taken into account (i.e., the ETS values obtained by the model are 0.14 and 0.18 for the Fuzzy-Basic and Fuzzy-All, respectively). False alarms for the TC forecasts covering the Week-1 period are greater in the Fuzzy-Basic than in the Fuzzy-All; the FAR values they obtained are 0.34 and 0.15 , respectively.

The performance of TC forecasts in longer period (i.e., for the Week-2) is not as good as for the Week-1 period. The HR values obtained by the model for the Week- 2 forecast period are even surpassed by the FAR values both for the Fuzzy-Basic and Fuzzy-All. As the main goal of this study is to evaluate the possible operational application of the CWB TC Tracker applied for the NCEP-GEFS in providing Week-1 and Week-2 TC activity forecasts over the PAR, the forecasting method with lower FAR, yet acceptable HR is preferred. Hence, the succeeding analyses focus on utilizing the Fuzzy-All as it provides more useful operational application than the Fuzzy-Basic in providing TC forecasts over the PAR.

\subsection{Effect of TC Characteristics on Predictability Over the PAR}

Figure 2 compares the entire tracks of correctly predicted and unpredicted TC events for the Week-1 period. Most of the TCs that were predicted one week prior to their occurrence formed far from the eastern boundary of the PAR toward the Pacific Ocean (Fig. 2a). In contrast, unpredicted TCs were mostly generated either inside the PAR or very close to its eastern boundary (Fig. 2b). Because most of the predicted TCs were formed farther east of the Philippines, they usually become more intense as compared to the unpredicted ones. Also, predicted TCs are generally re-curving, while the unpredicted TCs are characterized by northwestward trajectories making landfall over the Philippines.

Correctly predicted TCs for Week-1 forecast period have longer lifecycles and stay longer over the ocean prior to entering the PAR as compared to the unpredicted TCs (Fig. 3). On average, predicted TCs were already lingering over the Pacific Ocean for about $75 \mathrm{~h}$ prior to entering the PAR (marked by the horizontal line inside the box plot in Fig. 3a). In contrast, unpredicted TCs have almost no time 
Table 1. List of TCs that existed in the PAR in 2015 and 2017, which are included in this study. TC names in Italics are the local names assigned by PAGASA.

\begin{tabular}{|c|c|c|c|c|}
\hline TC Name & Start Date & End Date & Date of Entry in the PAR & Date of Exit in the PAR \\
\hline \multicolumn{5}{|c|}{2015} \\
\hline Mekkhala (Amang) & 00Z Jan 13 & 18Z Jan 20 & 00Z Jan 15 & $18 Z$ Jan 20 \\
\hline Bavi (Betty) & 06Z Mar 10 & 12Z Mar 21 & 12Z Mar 17 & 12Z Mar 21 \\
\hline Maysak (Chedeng) & $12 Z$ Mar 26 & 00Z Apr 7 & 18Z Apr 1 & 12Z Apr 5 \\
\hline Noul (Dodong) & 06Z May 2 & 00Z May 16 & 00Z May 7 & 15Z May 11 \\
\hline Linfa (Egay) & $18 \mathrm{Z}$ Jul 1 & 00Z Jul 10 & 18Z Jul 1 & 18Z Jul 6 \\
\hline Chan-Hom (Falcon) & 06Z Jun 29 & 00Z Jul 13 & $18 \mathrm{Z} \mathrm{Jul} 7$ & $15 Z$ Jul 9 \\
\hline Halola (Goring) & $18 \mathrm{Z} \mathrm{Jul} 12$ & $12 \mathrm{Z} \mathrm{Jul} 26$ & $12 \mathrm{Z} \mathrm{Jul} 23$ & $12 \mathrm{Z} \mathrm{Jul} 24$ \\
\hline Soudelor (Hanna) & $18 \mathrm{Z}$ Jul 29 & 00Z Aug 12 & 00Z Aug 5 & 06Z Aug 8 \\
\hline Goni (Ineng) & 18Z Aug 13 & 06Z Aug 30 & 06Z Aug 18 & $15 \mathrm{Z}$ Aug 23 \\
\hline Dujuan (Jenny) & 18Z Sep 19 & 06Z Sep 30 & 06Z Sep 23 & $18 Z$ Sep 28 \\
\hline Mujigae (Kabayan) & 18Z Sep 30 & $00 Z$ Oct 5 & 18Z Sep 30 & $12 Z$ Oct 2 \\
\hline Koppu (Lando) & 00Z Oct 12 & $06 Z$ Oct 21 & $12 \mathrm{Z}$ Oct 14 & $06 Z$ Oct 21 \\
\hline In-Fa (Marilyn) & $18 \mathrm{Z}$ Nov 16 & 06Z Nov 27 & $12 Z$ Nov 22 & $18 \mathrm{Z}$ Nov 24 \\
\hline Melor (Nona) & 00Z Dec 10 & 00Z Dec 17 & 00Z Dec 12 & 00Z Dec 17 \\
\hline Onyok & 06Z Dec 16 & $12 Z$ Dec 18 & 06Z Dec 16 & $12 Z$ Dec 18 \\
\hline \multicolumn{5}{|c|}{2017} \\
\hline Auring & 00Z Jan 7 & $18 Z$ Jan 8 & $00 \mathrm{Z} \operatorname{Jan} 7$ & $18 Z$ Jan 8 \\
\hline Bising & 06Z Feb 3 & 00Z Feb 6 & 06Z Feb 3 & 00Z Feb 6 \\
\hline Crising & 06Z Apr 14 & 06Z Apr 15 & 06Z Apr 14 & 06Z Apr 15 \\
\hline Muifa (Dante) & 18Z Apr 22 & 06Z Apr 29 & 06Z Apr 26 & $18 \mathrm{Z}$ Apr 27 \\
\hline Merbok & 00Z Jun 10 & 06Z Jun 13 & 00Z Jun 10 & 00Z Jun 11 \\
\hline Nanmadol (Emong) & 06Z Jul 1 & $12 \mathrm{Z} \mathrm{Jul} 8$ & 06Z Jul 1 & $18 \mathrm{Z}$ Jul 2 \\
\hline Roke (Fabian) & $18 \mathrm{Z}$ Jul 21 & 00Z Jul 22 & $18 \mathrm{Z}$ Jul 21 & 00Z Jul 22 \\
\hline Nesat (Gorio) & 06Z Jul 25 & 18Z Jul 30 & 06Z Jul 25 & $18 Z$ Jul 29 \\
\hline Haitang (Huaning) & $12 \mathrm{Z} \mathrm{Jul} 27$ & 18Z Aug 2 & 00Z Jul 30 & $18 \mathrm{Z} \mathrm{Jul} 30$ \\
\hline Hato (Isang) & 12Z Aug 19 & 00Z Aug 25 & 12Z Aug 19 & 00Z Aug 22 \\
\hline Pakhar (Jolina) & 00Z Aug 24 & 00Z Aug 28 & 00Z Aug 24 & 06Z Aug 26 \\
\hline Mawar & 06Z Aug 30 & 06Z Sep 4 & 06Z Aug 30 & $12 Z$ Aug 31 \\
\hline Guchol (Kiko) & $12 Z$ Sep 3 & $12 Z$ Sep 7 & $12 Z$ Sep 3 & $12 Z$ Sep 6 \\
\hline Talim (Lannie) & $12 Z$ Sep 8 & $18 Z$ Sep 22 & 06Z Sep 11 & 06Z Sep 13 \\
\hline Doksuri (Maring) & 00Z Sep 10 & 00Z Sep 16 & 00Z Sep 10 & 06Z Sep 13 \\
\hline Nando & 06Z Sep 23 & $12 Z$ Sep 23 & 06Z Sep 23 & $12 Z$ Sep 23 \\
\hline Khanun (Odette) & 00Z Oct 11 & 06Z Oct 16 & 00Z Oct 11 & $06 Z$ Oct 14 \\
\hline Lan (Paolo) & $06 Z$ Oct 15 & $18 Z$ Oct 23 & $12 Z$ Oct 16 & $15 Z$ Oct 21 \\
\hline Saola (Quedan) & $06 Z$ Oct 22 & $12 Z$ Oct 29 & $12 \mathrm{Z}$ Oct 25 & $21 \mathrm{Z}$ Oct 27 \\
\hline Damrey (Ramil) & 00Z Oct 31 & $18 \mathrm{Z}$ Nov 4 & 00Z Oct 31 & $12 Z$ Nov 2 \\
\hline Haikui (Salome) & $12 Z$ Nov 7 & 00Z Nov 13 & $12 Z$ Nov 7 & $18 \mathrm{Z}$ Nov 10 \\
\hline Kirogi (Tino) & $12 Z$ Nov 16 & 06Z Nov 19 & $12 Z$ Nov 16 & 00Z Nov 18 \\
\hline Kai-Tak (Urduja) & $18 Z$ Dec 13 & $18 \mathrm{Z}$ Dec 23 & $18 \mathrm{Z}$ Dec 13 & 06Z Dec 19 \\
\hline Tembin (Vinta) & 00Z Dec 20 & 06Z Dec 26 & 00Z Dec 20 & $18 \mathrm{Z}$ Dec 23 \\
\hline
\end{tabular}


Table 2. Summary of verification metrics obtained by the CWB TC Tracker for NCEPGEFS in Week-1 and Week-2 forecasts of TC activity over the PAR comparing the Fuzzy-Basic and Fuzzy-All criteria.

\begin{tabular}{c|cc|cc}
\hline \multirow{2}{*}{ Verification Metric } & \multicolumn{2}{|c|}{ Fuzzy-Basic } & \multicolumn{2}{c}{ Fuzzy-All } \\
\cline { 2 - 5 } & Week-1 & Week-2 & Week-1 & Week-2 \\
\hline Hit Rate (HR) & 0.60 & 0.27 & 0.49 & 0.19 \\
Equitable Threat Score (ETS) & 0.14 & -0.11 & 0.18 & -0.04 \\
Frequency Bias (FB) & 0.81 & 0.60 & 0.58 & 0.36 \\
False Alarm Rate (FAR) & 0.34 & 0.56 & 0.15 & 0.28 \\
\hline
\end{tabular}

(a)

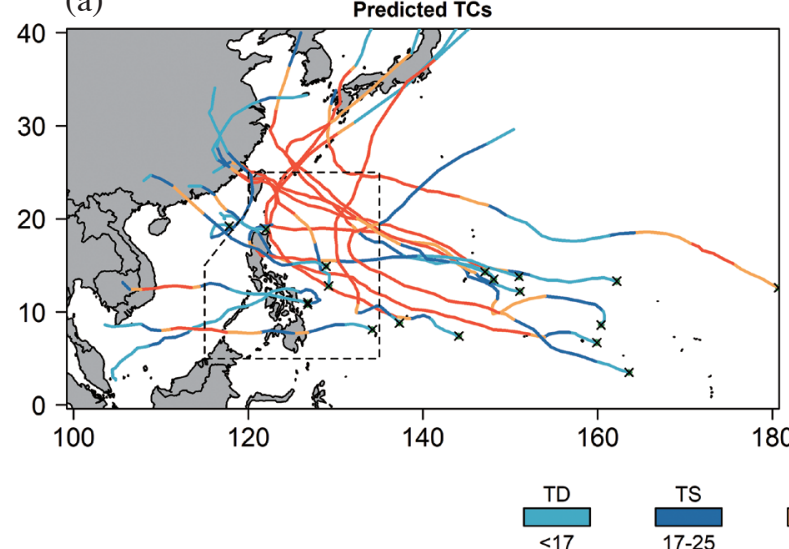

(b)

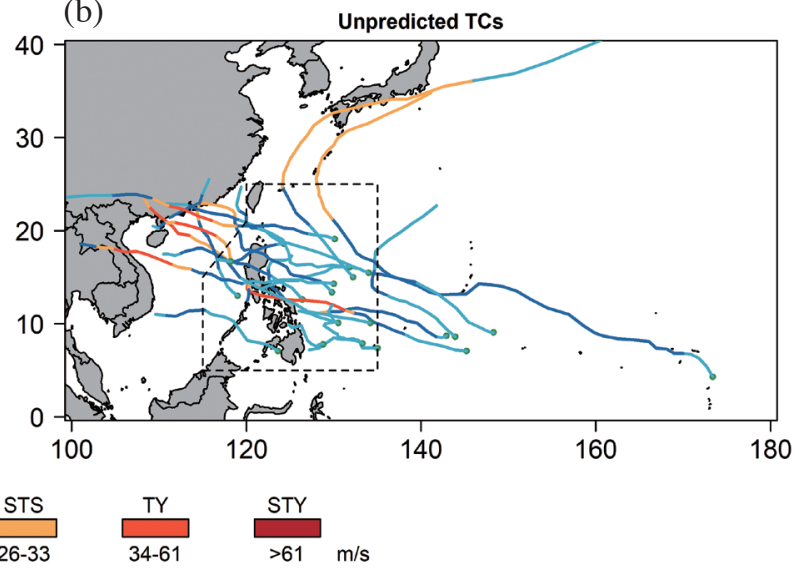

Fig. 2. Comparison of the tracks of (a) correctly predicted TCs and (b) unpredicted TCs covering the Week-1 forecast period. Colors indicate TC intensities categorized based on the definition operationally being used by PAGASA: TD - Tropical Depression, TS - Tropical Storm, STS - Severe Tropical Storm, TY - Typhoon, and STY - Super Typhoon; green dots mark the areas where TCs were formed (i.e., genesis location). Areas marked with " $x$ " in (a) indicate the initial position of the TCs when forecast hit was obtained by the model.

(a)

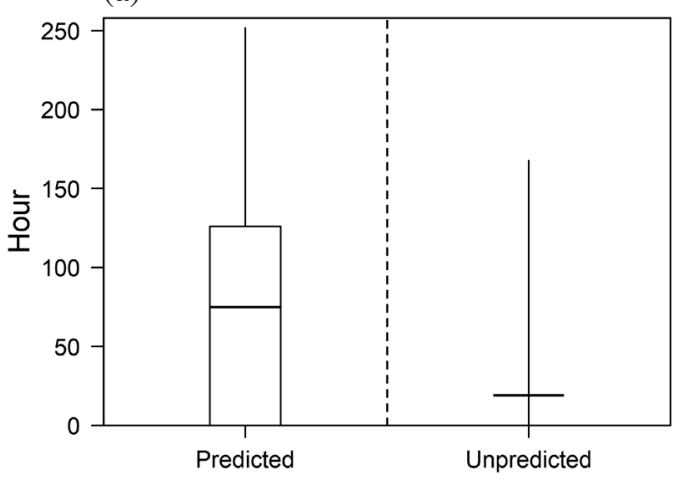

(b)

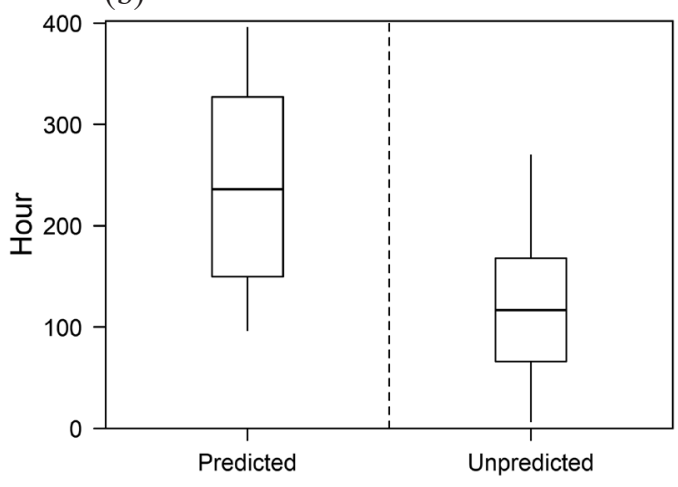

Fig. 3. Comparison of temporal characteristics of predicted and unpredicted TCs for Week-1 forecast period in the PAR in 2015 and 2017 . The whiskers in (a) indicate the longest and the shortest time the TC has stayed outside the PAR prior to entering the area, while these values correspond to the entire lifecycle of the TCs in (b). The boxes cover the interquartile range, while horizontal lines inside the boxes mark the mean. 
spent outside the PAR; an average value of $19 \mathrm{~h}$ is obtained across all TCs prior to entering the PAR, and thus more difficult to be predicted a week ahead of their existence. It is further revealed that the predicted TCs have longer lifecycles $(236 \mathrm{~h}$, on average) than the unpredicted TCs $(117 \mathrm{~h}$, averaged across all the TCs) (marked by the horizontal line inside the box plot in Fig. 3b).

These TC characteristics, which include formation farther to the eastern boundary of the PAR toward the Pacific Ocean, more intense, and with longer lifecycles are the common TC characteristics during an El Niño event (e.g., Camargo and Sobel 2005; Camargo et al. 2007; Cinco et al. 2016). Interestingly, 2015 is categorized a strong El Niño year (e.g., Zhai et al. 2016), while in 2017, neutral ENSO conditions prevailed until the third quarter and then turned into a La Niña condition later in the fourth quarter of that year. Figure $4 \mathrm{a}$ confirms that the TCs that existed in the PAR in 2015 were formed far from the eastern boundary of the PAR toward the Pacific Ocean. They are also of higher intensities, $73 \%$ of the TCs in 2015 reached typhoon categories. In contrast, the TCs in 2017 are mainly dominated by tropical depression and tropical storm categories that were mostly formed either inside or very close to the eastern border of the PAR (Fig. 4b).

Figure 5 compares the verification metrics obtained by the TC tracking results for Week-1 and Week-2 TC forecasts over the PAR in 2015 and 2017. For Week-1, the HR value obtained by the model in 2015 is higher than in 2017 ( 0.55 and 0.44 , respectively). The difference between the two investigated years even become more apparent when the TC forecast hit due to random chance is taken into account; the ETS value obtained by the model in forecasting TCs over the PAR for the Week-1 period in 2015 is almost double that of 2017 (i.e., 0.24 and 0.13 , respectively). In both years, the FB values obtained by the model are below 1.0 indicating under forecasting of TC events. For the 2-week lead-time forecasts, the CWB TC Tracker for NCEP-GEFS obtained HR values that are almost the same between the two years of investigated period. Similarly, the ETS values for the Week-2 period are very close to zero (-0.03 for both years). Also, the FAR values obtained by the model both in 2015 and 2017 are higher than their HR. These findings suggest that the ENSO condition is primarily helpful only for the Week-1 forecast period over the PAR.

\subsection{MJO Influence on TC Predictability Over the PAR}

In addition to the TC characteristics described in the previous section, which suggest the influence of ENSO condition on Week-1 TC predictability over the PAR, Belanger et al. (2010) have shown that TC forecasts are also sensitive to the MJO phase during the model's initialization time. We then investigated whether the MJO has an influence on TC predictability over the PAR both for the 1- and 2-week lead times. Here, the MJO index developed by Wheeler and Hendon (2004) is used as it offers practical real-time application. The MJO index characterizes the state of the MJO based on a phase-space diagram; an amplitude value of the index $>1.0$ indicates an active phase coinciding to an enhanced convection over a particular equatorial region - Africa and the western Indian Ocean for the phase 1, the Indian Ocean for phases $2-3$, the Maritime Continent in phases 4 - 5, the western Pacific Ocean in phases 6 - 7, and the Western Hemisphere in phase 8.

To investigate the influence of MJO on TC predictability over the PAR, the TC tracking results based on the NCEP-GEFS for the Week-1 and Week-2 periods are pooled conditionally (based on the forecast initialization times) with the active state of the MJO from phases 1 to 8 . Figure 6 shows the daily time series depicting an eastward propagation of the location of enhanced convection of the MJO (from phase 1 to 8; blue-shaded strips). According to Wheeler and Hendon (2004) the transition time it takes from one phase to another of the active MJO is about six days, but varies from one event to another as observed both in 2015 and 2017 (Figs. 6a and b, respectively). The days with valid initialization of the NCEP-GEFS TC forecasts, as well as when there is a TC in the PAR, are also marked in Fig. 6 (black dots and red-shaded strips, respectively). Considering all the 6-hourly forecasts of the NCEP-GEFS used in this study, $53 \%$ of the initialization times fall during an active MJO phase. The MJO active phases 1 and 2 both have shared equally with $7 \%$ of all the model initialization times. For the MJO active phases $3-5$, all have $6 \%$ each of all the model initialization times. Five-, eleven-, and five-percent $(5,11$, and $5 \%)$ of all the model initializations were during the active MJO at phases 6,7, and 8, respectively.

The verification metrics and the parameters obtained by the CWB TC Tracker for NCEP-GEFS in predicting TC activity over the PAR for the Week-1 forecast period considering all the TC tracking outputs and when the initialization time coincide with an active MJO at phases $1-8$ are summarized in Table 3 . The highest HR value $(0.8)$ is obtained when the initialization time of the model coincides with an active MJO at phase 1. The ETS value has also increased more than three-folds from its original value (when all the model runs were considered), and the FAR is lowered from 0.15 to 0.06 when considering only those Week- 1 TC forecasts issued when the initialization time of the NCEPGEFS falls under an active MJO at phase 1. These suggest a better predictability of TC activity over the PAR one week ahead of time when the active convection phase of the MJO is located over Africa and the western Indian Ocean.

The TC tracks where forecast hits were obtained by the model for Week-1 forecast period and when the initialization time occurs during an active $\mathrm{MJO}$ at phase 1 are shown in Fig. 7. Six of the TCs (four in 2015 namely, Maysak, Halola, Soudelor, and Goni while two TCs in 2017, which 
(a)

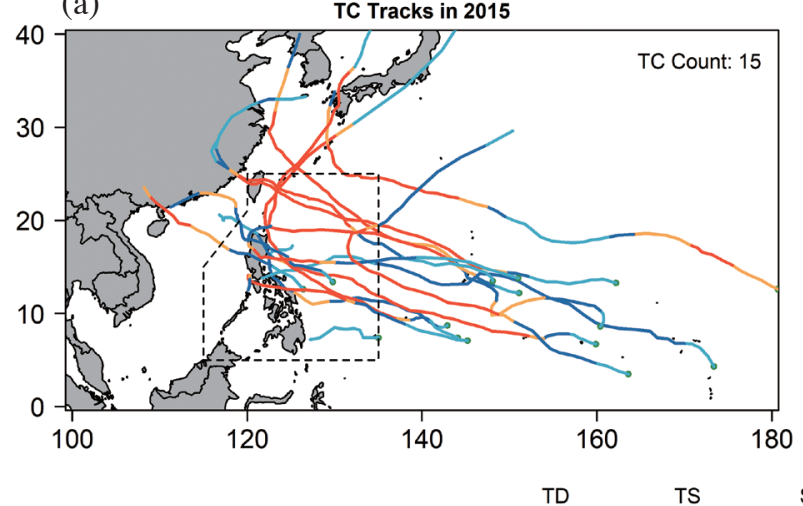

(b)

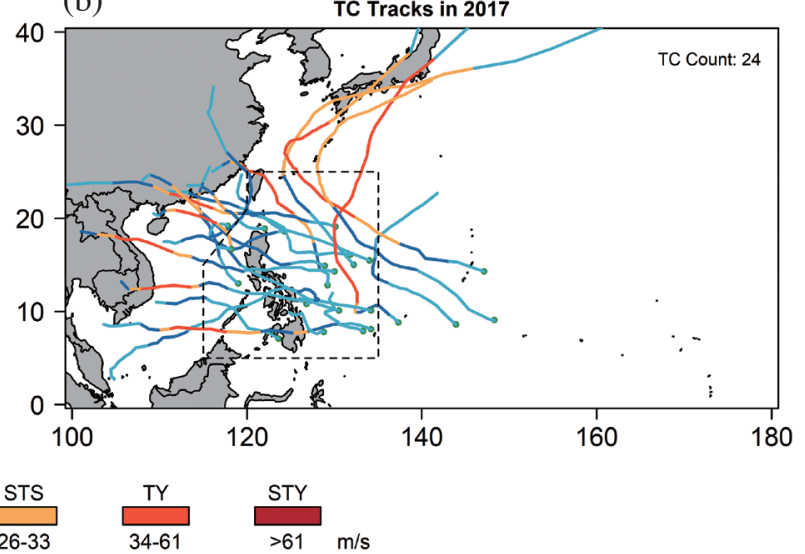

Fig. 4. Tracks of TCs that existed in the PAR in (a) 2015 and (b) 2017. Colors indicate TC intensities categorized based on the definition operationally being used by PAGASA: TD - Tropical Depression, TS - Tropical Storm, STS - Severe Tropical Storm, TY - Typhoon, and STY - Super Typhoon.
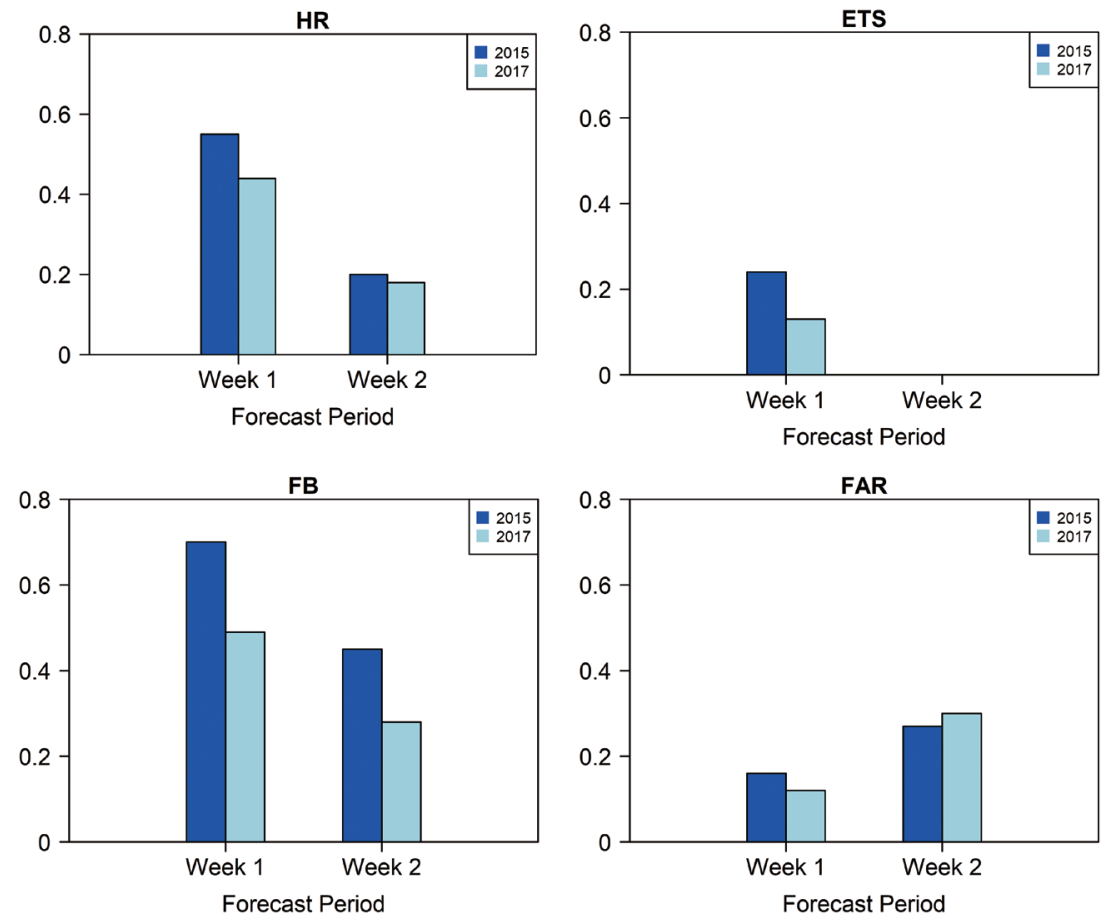

Fig. 5. Comparison of verification metrics obtained by the NCEP-GEFS for TC forecasts over the PAR covering Week-1 and Week-2 periods in 2015 and 2017 

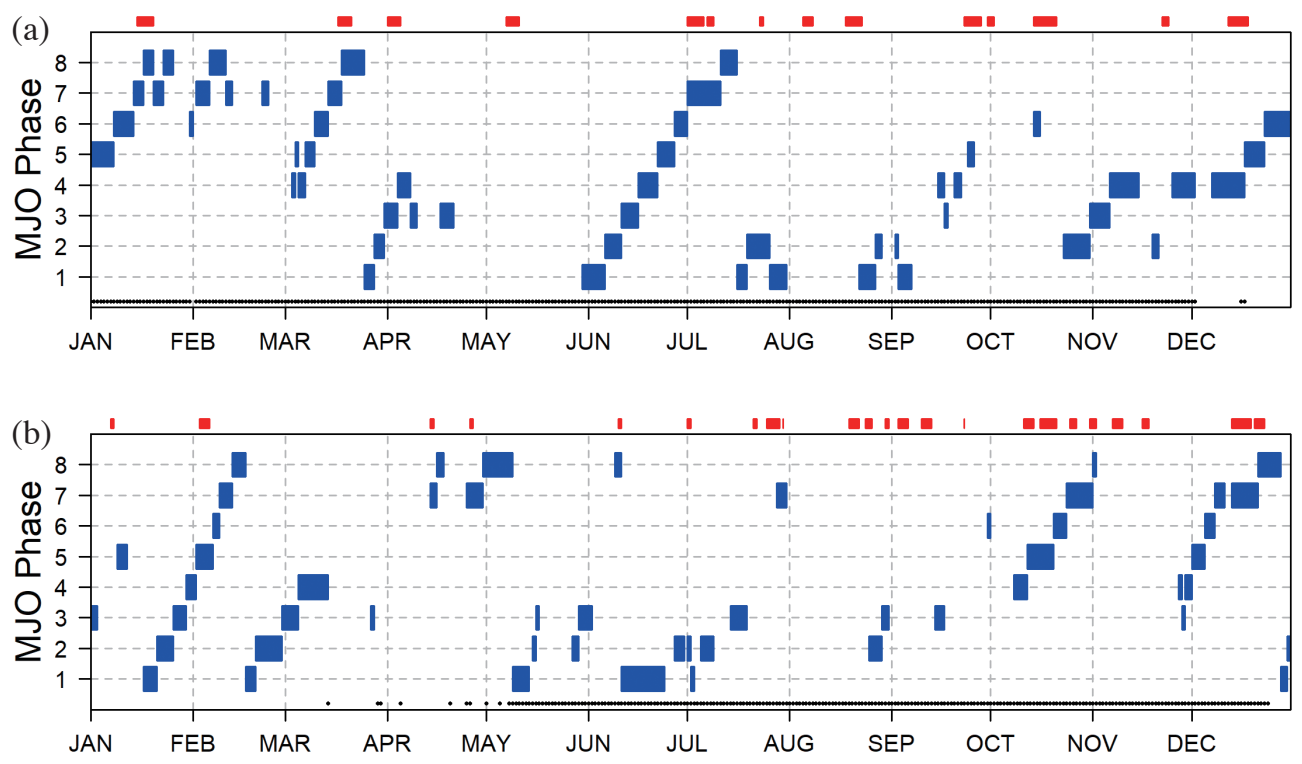

Fig. 6. Time series depicting the events of active MJO phase (blue-shaded boxes) and available TC forecasts derived from the NCEP-GEFS model (black dots near the abscissa) in (a) 2015 and (b) 2017. Red markings on top of each panel indicate an existence of TC inside the PAR; the exact dates of TC occurrence are provided in Table 1.

Table 3. List of parameters and verification metrics obtained by the CWB TC Tracker for NCEP-GEFS in Week-1 forecasts of TC activity over the PAR comparing the different values obtained when the NCEP-GEFS initialization times coincide to an active convection of the MJO at phases 1 - 8. All the parameters and metrics were defined in the text.

\begin{tabular}{c|ccccccccc}
\hline & $\boldsymbol{a}$ & $\boldsymbol{b}$ & $\boldsymbol{c}$ & $\boldsymbol{d}$ & Total & HR & ETS & FB & FAR \\
\hline All* & 803 & 154 & 841 & 900 & 2698 & 0.49 & 0.18 & 0.58 & 0.15 \\
Ph 1 & 48 & 7 & 12 & 109 & 176 & 0.80 & 0.61 & 0.92 & 0.06 \\
Ph 2 & 64 & 15 & 29 & 94 & 202 & 0.69 & 0.39 & 0.85 & 0.14 \\
Ph 3 & 38 & 1 & 38 & 89 & 166 & 0.50 & 0.34 & 0.51 & 0.01 \\
Ph 4 & 29 & 26 & 37 & 77 & 169 & 0.44 & 0.11 & 0.83 & 0.25 \\
Ph 5 & 47 & 10 & 68 & 46 & 171 & 0.41 & 0.10 & 0.50 & 0.18 \\
Ph 6 & 36 & 1 & 73 & 15 & 125 & 0.33 & 0.05 & 0.34 & 0.06 \\
Ph 7 & 145 & 15 & 111 & 34 & 305 & 0.57 & 0.08 & 0.62 & 0.31 \\
Ph 8 & 39 & 5 & 40 & 43 & 127 & 0.49 & 0.21 & 0.56 & 0.10 \\
\hline
\end{tabular}

Note: * This corresponds to when all the Week-1 TC forecasts were included. 


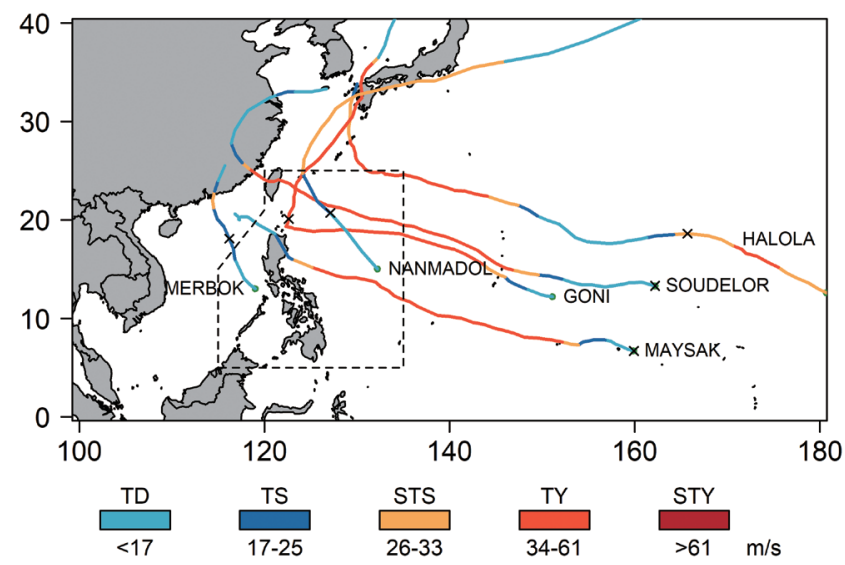

Fig. 7. Tracks of the TCs in which Week-1 forecast hits are obtained by the NCEP-GEFS and when the initialization times of the model coincide to the active state of the MJO at phase 1. The locations marked with " $x$ " indicate the initial position of the TCs when forecast hit was obtained by the model during which the NCEP-GEFS initialization times coincide to an active MJO at phase 1.

include Merbok and Nanmadol) were forecasted correctly by the model. Note, however, that some of the TCs namely, Halola, Goni, Nanmadol, and Merbok, have already been predicted correctly in the Week-1 TC forecasts prior to the issuance coinciding to the active $\mathrm{MJO}$ at phase 1 (this can be confirmed by comparing the " $\mathrm{x}$ " markers in Figs. 2a and 7 indicating the initial point of the TC when forecast hit was obtained). The model was only able to predict the initial points of Maysak and Soudelor, implying that the active convection of the MJO is already in place at phase 1 when the Week-1 TC forecasts were issued and forecast hits were obtained for these two TCs.

Table 4 compares the different metrics obtained for Week-2 TC forecasts over the PAR. The highest HR obtained by the TC forecasts is 0.34 and that is when the model is initialized coinciding to the active convection phase of MJO at phase 6 (over the western Pacific Ocean). However, in comparison to all the model forecasts issued for Week-2, the FAR is almost doubled (from 0.28 to 0.48 ) when the NCEP-GEFS model initialization times coincide with the active convection of the MJO at phase 6. Nevertheless, a notable improvement of the model skill is attained when the model initialization time coincides with the active MJO at phase 5 (over the Maritime Continent); the HR value is increased from 0.19 to 0.30 and the FAR is decreased from 0.28 to 0 . This means that for operational application, the improvement brought by the TC forecasts is only useful when the initialization time coincides to the active MJO specifically, at phase 5 .

The tracks of TCs that are correctly forecasted by the model for the Week-2 forecast period in the PAR and in which the NCEP-GEFS initialization times coincide to the active MJO at phase 5 are shown in Fig. 8. Four of these TCs namely, Mekkhala, Bavi, Linfa, and Chan-Hom occurred in 2015, while three of them (Lan, Damrey, and KaiTak) occurred in 2017. Notably, these TCs were generated east of the Philippines and south of $10^{\circ} \mathrm{N}$ (except for Linfa that is formed slightly north of $10^{\circ} \mathrm{N}$ ). Such characteristics might be linked to the higher chances of TC development over the WNP when the active convection phase of the MJO is on its Phase 7 (e.g., Liebmann et al. 1994; Sobel and Maloney 2000). Note that, as mentioned earlier, it takes about 6 days for the MJO to transition from one phase to another. This means that it takes approximately two weeks for the active convection phase of the MJO to transition from phase 5 to phase 7 , indicating that perhaps the TCs that formed two weeks later from the model's initialization time (which are forecasted correctly) were initiated by the enhanced convection phase of the MJO that travelled approximately two weeks from the Maritime Continent (phase 5) to the western Pacific (phase 7). Similar to the Week-1 TC forecasts, it has to be noted as well that in some cases, Week-2 TC forecast hits have already been obtained prior to the onset of the MJO at phase 5, such as in the case of Bavi and Lan. Nevertheless, the Week-2 TC forecasts issued during an active MJO at phase 5 for the other five TCs (Chan-Hom, Mekkhala, Linfa, Damrey, and Kai-Tak), obtained the forecast hit from their starting point.

To further explain the reasons behind the improved TC forecasting skill for Week-1 (Week-2) when the MJO active convection is at phase 1 (5), some of the environmental conditions known to affect TC formation and development are investigated. The composites of June-JulyAugust-September vertical wind shear (i.e., $U_{200}$ minus $U_{850}$ ) and the positive 850 -hPa relative vorticity obtained from the JRA-55 are presented in Fig. 9. The composites were obtained from days with available model forecasts and when the CWB TC Tracker for NCEP-GEFS obtained a TC forecast hit. Figure 9a shows that favorable conditions for TC formation and further development prevail over and around the Philippines (i.e., weak vertical wind shear and with positive relative vorticities elongated almost along the 
Table 4. As in Table 3, but for the Week-2 TC forecasts over the PAR.

\begin{tabular}{l|ccccccccc}
\hline & $\boldsymbol{a}$ & $\boldsymbol{b}$ & $\boldsymbol{c}$ & $\boldsymbol{d}$ & Total & HR & ETS & FB & FAR \\
\hline All* & 314 & 281 & 1347 & 733 & 2675 & 0.19 & -0.04 & 0.36 & 0.28 \\
Ph 1 & 12 & 35 & 64 & 78 & 189 & 0.16 & -0.07 & 0.62 & 0.31 \\
Ph 2 & 5 & 25 & 90 & 87 & 207 & 0.05 & -0.08 & 0.32 & 0.22 \\
Ph 3 & 0 & 11 & 108 & 77 & 196 & 0.00 & -0.05 & 0.10 & 0.12 \\
Ph 4 & 22 & 11 & 120 & 48 & 201 & 0.15 & -0.01 & 0.23 & 0.19 \\
Ph 5 & 49 & 0 & 112 & 2 & 163 & 0.30 & 0.01 & 0.30 & 0.00 \\
Ph 6 & 40 & 11 & 79 & 12 & 142 & 0.34 & -0.03 & 0.43 & 0.48 \\
Ph 7 & 31 & 33 & 115 & 58 & 237 & 0.21 & -0.06 & 0.44 & 0.36 \\
Ph 8 & 2 & 19 & 47 & 30 & 98 & 0.04 & -0.15 & 0.43 & 0.39 \\
\hline
\end{tabular}

Note: * This corresponds to when all the Week-2 TC forecasts were included.

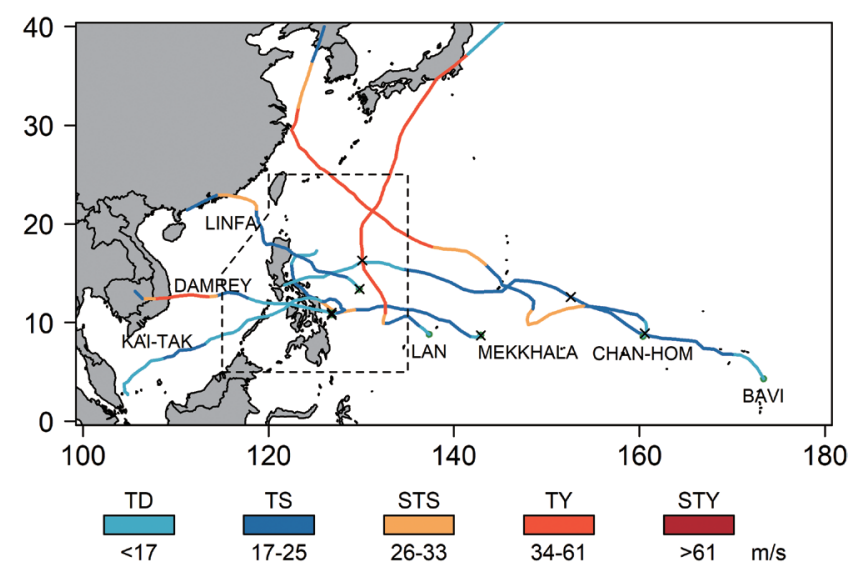

Fig. 8. Tracks of the TCs in which Week-2 forecast hits are obtained by the NCEP-GEFS and when the initialization times of the model coincide to the active state of the MJO at phase 5. The locations marked with " $x$ " indicate the initial position of the TCs when forecast hit was obtained by the model and during which the NCEP-GEFS initialization times coincide to an active MJO at phase 5.

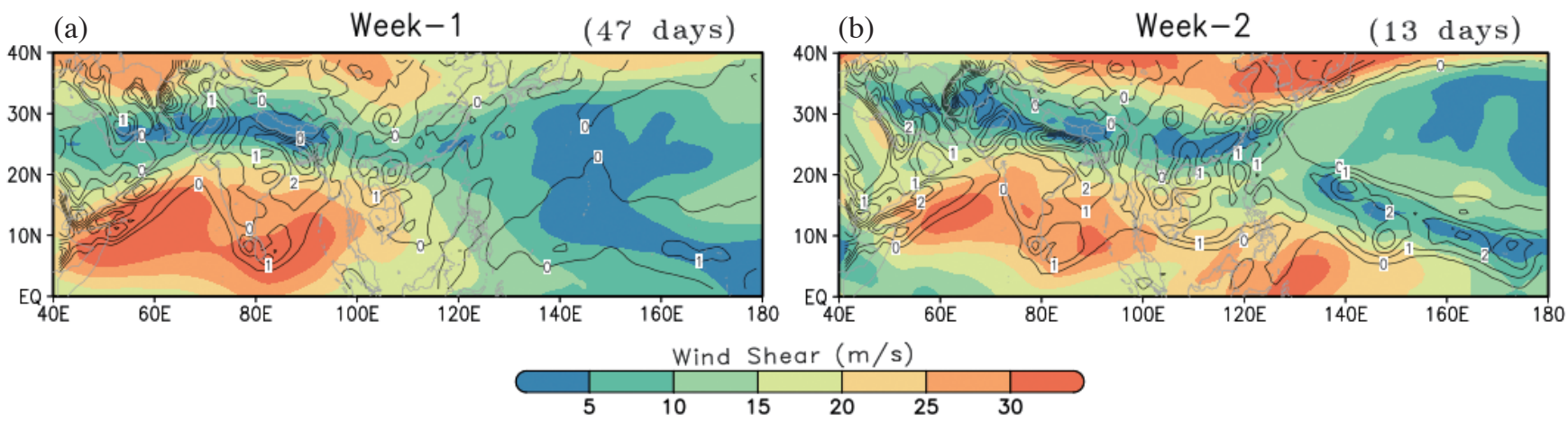

Fig. 9. Composite maps of June to September vertical wind shear (shadings) and positive 850 -hPa relative vorticity $\left(\right.$ contours; $\left.\times 10^{-5} \mathrm{~s}^{-1}\right)$ obtained from (a) Week-1 forecast period when the model initialization times coincide with the active convection phase of MJO at Phase 1 and (b) Week-2 forecast period when the model initialization times coincide with the active convection phase of MJO at Phase 5. The number of days included to obtain the composites are provided on the upper right corner of the maps; only those days with available model forecasts and when the model obtained a forecast hit were included. 
monsoon trough region) during the Week-1 forecast period when the model initialization times coincide with the active MJO at phase 1 . These conditions partly explain, in addition to those that are noted earlier, why better TC forecast skills were obtained when the model initialization times coincide with the active MJO at phase 1. Similarly, favorable conditions are observed for Week-2 forecast period when the model initialization times occur during an active MJO at phase 5 (Fig. 9b), providing one of the possible reasons for better forecast skills obtained by the model.

\section{CONCLUSIONS}

We have investigated the potential predictability of 2015 and 2017 TC occurrences (including their subsequent movement path) in the PAR by using the CWB TC Tracker for NCEP-GEFS 16-day forecasts. An objective method of evaluation that compares similarity between the TC track forecasts and observations indicates a skill in predicting TC activity over the PAR for lead times extending to two weeks. The model obtained HR values of 0.49 and 0.19 , respectively for the TC forecasts provided on Week- 1 and Week-2 forecast periods covering the entire 2015 and 2017. We found that TC characteristics affect predictability in such a way that TCs of higher intensities, longer lifecycles, and developed farther to the eastern border of the PAR have higher chances of getting predicted one week ahead of their occurrence in the PAR. Such characteristics are typically being observed during El Niño events (Camargo and Sobel 2005; Camargo et al. 2007; Cinco et al. 2016), as in the case of 2015. Comparing the model skill during the two-year period of evaluation indicates that better TC predictability for Week-1 was obtained in $2015(\mathrm{HR}=0.55$ and ETS $=0.24)$ than in 2017 (HR $=0.44$ and ETS $=0.13$ ) confirming better predictability of Week-1 TC activity over the PAR during an El Niño using the CWB TC Tracker for NCEP-GEFS.

It has also been demonstrated that the MJO plays an important role in the predictability of TC activity over the PAR. We found that when the NCEP-GEFS is initialized during an active $\mathrm{MJO}$ at Phase 1, the model obtains a higher HR value (from 0.49 to 0.8 ) and a more than three-folds increase in ETS (from 0.18 to 0.61 ) for the Week-1 forecast period. The results further revealed that when the model initialization time coincides with an active convection phase of the MJO over the Maritime Continent (i.e., phase 5), an improved model skill $(\mathrm{HR}=0.30 ; \mathrm{FAR}=0)$ is obtained for the Week-2 forecast period. These suggest a higher predictability of TC activity over the PAR one- (two-) week in advance when the active convection phase of the MJO is located over Africa and the western Indian Ocean (the Maritime Continent). It has been noted, however, that some TCs might have already been existing in the area or earlier forecast hits have already been obtained prior to the onset of the active convection phase of MJO when TC forecasts were issued, and thus, might have led to the better predictability. Nevertheless, favorable environmental conditions (characterized with weak vertical wind shear associated with positive relative vorticity) have prevailed over and around the Philippines, particularly over the areas where TCs were formed and further developed during the Week-1 (Week-2) TC forecast periods when the MJO is active at phase 1 (phase 5).

The findings illustrated in this study have been found useful and served as a benchmark for providing TC forecasts on weekly timescales over the PAR. Such TC forecasts, although preliminary in nature, complement existing initiatives such as those being provided by the CPC (see, https://www.cpc.ncep.noaa.gov/products/precip/CWlink/ ghazards/index.php) that are beneficial in many aspects of climate information over the Philippines (e.g., Villafuerte II et al. 2017). We note, however, that further analyses covering a longer period to include more ENSO and MJO cases would be helpful to increase our understanding and obtain more robust conclusions. The authors are currently involved in such initiatives to complement the preliminary findings reported in this study.

Acknowledgements We acknowledge the collaborative efforts extended to us by Mr. Robert R. Badrina in the earlier stage of this study. We thank the Manila Economic Cooperation and Taiwan Economic Cooperation (MECO-TECO) VOTE program and the partial funding support provided by the Department of Science and Technology through the Philippine Council for Industry, Energy and Emerging Technology Research and Development (PCIEERD) to the said program, which enabled us to pursue this work. We are also thankful to the Central Weather Bureau for providing the outputs of CWB TC Tracker and its continuous support to maintain the system. The constructive criticisms and helpful suggestions provided by the anonymous reviewers are sincerely acknowledged as well.

\section{REFERENCES}

Bagtasa, G., 2017: Contribution of tropical cyclones to rainfall in the Philippines. J. Clim., 30, 3621-3633, doi: 10.1175/jcli-d-16-0150.1. [Link]

Belanger, J. I., J. A. Curry, and P. J. Webster, 2010: Predictability of North Atlantic tropical cyclone activity on intraseasonal time scales. Mon. Weather Rev., 138, 4362-4374, doi: 10.1175/2010mwr3460.1. [Link]

Biswas, M. K., D. Stark, and L. Carson, 2018: GFDL Vortex Tracker: Users' Guide V3.9a, Developmental Testbed Center, Boulder, CO, USA, 35 pp.

Camargo, S. J. and A. H. Sobel, 2005: Western North Pacific tropical cyclone intensity and ENSO. J. Clim., 18, 2996-3006, doi: 10.1175/jcli3457.1. [Link]

Camargo, S. J., K. A. Emanuel, and A. H. Sobel, 2007: Use 
of a genesis potential index to diagnose ENSO effects on tropical cyclone genesis. J. Clim., 20, 4819-4834, doi: $10.1175 /$ jcli4282.1. [Link]

Chan, J. C.L., J. Shi, and C. Lam, 1998: Seasonal forecasting of tropical cyclone activity over the western North Pacific and the South China Sea. Weather Forecast., 13, 997-1004, doi: 10.1175/1520-0434(1998)013<0997:SF OTCA > 2.0.CO;2. [Link]

Cinco, T. A., R. G. de Guzman, A. M. D. Ortiz, R. J. P. Delfino, R. D. Lasco, F. D. Hilario, E. L. Juanillo, R. Barba, and E. D. Ares, 2016: Observed trends and impacts of tropical cyclones in the Philippines. Int. J. Climatol., 36, 4638-4650, doi: 10.1002/joc.4659. [Link]

Corporal-Lodangco, I. L., L. M. Leslie, and P. J. Lamb, 2016: Impacts of ENSO on Philippine tropical cyclone activity. J. Clim., 29, 1877-1897, doi: 10.1175/jclid-14-00723.1. [Link]

Elsberry, R. L., 2014: Advances in research and forecasting of tropical cyclones from 1963-2013. Asia-Pac. J. Atmos. Sci., 50, 3-16, doi: 10.1007/s13143-014-0001-1. [Link]

Elsberry, R. L., M. S. Jordan, and F. Vitart, 2010: Predictability of tropical cyclone events on intraseasonal timescales with the ECMWF monthly forecast model. Asia-Pac. J. Atmos. Sci., 46, 135-153, doi: 10.1007/ s13143-010-0013-4. [Link]

Elsberry, R. L., H.-C. Tsai, and M. S. Jordan, 2014: Extended-range forecasts of Atlantic tropical cyclone events during 2012 using the ECMWF 32-day ensemble predictions. Weather Forecast., 29, 271-288, doi: 10.1175/waf-d-13-00104.1. [Link]

Hodges, K. I., 1995: Feature tracking on the unit sphere. Mon. Weather Rev., 123, 3458-3465, doi: 10.1175/1520-0493(1995)123<3458:FTOTUS>2.0. $\mathrm{CO} ; 2$. [Link]

Kobayashi, S., Y. Ota, Y. Harada, A. Ebita, M. Moriya, H. Onoda, K. Onogi, H. Kamahori, C. Kobayashi, H. Endo, K. Miyaoka, and K. Takahashi, 2015: The JRA55 reanalysis: General specifications and basic characteristics. J. Meteorol. Soc. Jpn., 93, 5-48, doi: 10.2151/ jmsj.2015-001. [Link]

Liebmann, B., H. H. Hendon, and J. D. Glick, 1994: The relationship between tropical cyclones of the western Pacific and Indian Oceans and the Madden-Julian Oscillation. J. Meteorol. Soc. Jpn., 72, 401-412, doi: 10.2151/jmsj1965.72.3_401. [Link]

Manganello, J. V., K. I. Hodges, J. L. Kinter, B. A. Cash, L. Marx, T. Jung, D. Achuthavarier, J. M. Adams, E. L. Altshuler, B. Huang, E. K. Jin, C. Stan, P. Towers, and N. Wedi, 2012: Tropical cyclone climatology in a $10-\mathrm{km}$ global atmospheric GCM: toward weatherresolving climate modeling. J. Clim., 25, 3867-3893, doi: 10.1175/jcli-d-11-00346.1. [Link]

Patricola, C. M., S. J. Camargo, P. J. Klotzbach, R. Sarava- nan, and P. Chang, 2018: The influence of ENSO flavors on western North Pacific tropical cyclone activity. J.Clim., 31, 5395-5416, doi: 10.1175/jcli-d-17-0678.1. [Link]

Redmond, G., K. I. Hodges, C. McSweeney, R. Jones, and D. Hein, 2015: Projected changes in tropical cyclones over Vietnam and the South China Sea using a $25 \mathrm{~km}$ regional climate model perturbed physics ensemble. Clim. Dyn., 45, 1983-2000, doi: 10.1007/s00382-0142450-8. [Link]

Sobel, A. H. and E. D. Maloney, 2000: Effect of ENSO and the MJO on western North Pacific tropical cyclones. Geophys. Res. Lett., 27, 1739-1742, doi: 10.1029/1999g1011043. [Link]

Tsai, H.-C. and R. L. Elsberry, 2013: Opportunities and challenges for extended-range predictions of tropical cyclone impacts on hydrological predictions. J. Hydrol., 506, 42-54, doi: 10.1016/j.jhydrol.2012.12.025. [Link]

Tsai, H.-C., K.-C. Lu, R. L. Elsberry, M.-M. Lu, and C.H. Sui, 2011: Tropical cyclone-like vortices detection in the NCEP 16-day ensemble system over the western North Pacific in 2008: Application and forecast evaluation. Weather Forecast., 26, 77-93, doi: 10.1175/2010waf2222415.1. [Link]

Tsai, H.-C., R. L. Elsberry, M. S. Jordan, and F. Vitart, 2013: Objective verifications and false alarm analyses of western North Pacific tropical cyclone event forecasts by the ECMWF 32-day ensemble. Asia-Pac. J. Atmos. Sci., 49, 409-420, doi: 10.1007/s13143-0130038-6. [Link]

Villafuerte II, M. Q., E. L. Juanillo, and F. D. Hilario, 2017: Climatic insights on academic calendar shift in the Philippines. Philippine Journal of Science, 146, 267-276.

Villafuerte II, M. Q., J. C. R. Lambrento, K. I. Hodges, F. T. Cruz, T. A. Cinco, and G. T. Narisma, 2021: Sensitivity of tropical cyclones to convective parameterization schemes in RegCM4. Clim. Dyn., 56, 1625-1642, doi: 10.1007/s00382-020-05553-3. [Link]

Vitart, F., 2009: Impact of the Madden Julian Oscillation on tropical storms and risk of landfall in the ECMWF forecast system. Geophys. Res. Lett., 36, L15802, doi: 10.1029/2009g1039089. [Link]

Vitart, F. and A. Brown, 2019: S2S Forecasting: Towards seamless prediction. WMO Bulletin, 68, 70-74.

Wheeler, M. C. and H. H. Hendon, 2004: An all-season real-time multivariate MJO index: development of an index for monitoring and prediction. Mon. Weather Rev., 132, 1917-1932, doi: 10.1175/1520-0493(2004)132<1917:AARMMI>2.0. CO;2. [Link]

Wilks, D. S., 2011: Statistical Methods in the Atmospheric Sciences, $3^{\text {rd }}$ Edition, Academic Press, 704 pp.

WMO, 1966: Regional Association V (South-West Pacific): 
Abridged Final Report of the Fourth Session. WMO No. 187, RP. 69, World Meteorological Organization, Geneva, Switzerland, 96 pp. Available at https://library.wmo.int/doc num.php?explnum id=7995. (Accessed 11 June 2021)

Yumul, G. P., N. A. Cruz, N. T. Servando, and C. B. Dimalanta, 2011: Extreme weather events and related disasters in the Philippines, 2004-08: A sign of what climate change will mean? Disasters, 35, 362-382, doi: 10.1111/j.1467-7717.2010.01216.x. [Link]
Zhai, P., R. Yu, Y. Guo, Q. Li, X. Ren, Y. Wang, W. Xu, Y. Liu, and Y. Ding, 2016: The Strong El Niño of 2015/16 and its dominant impacts on global and China's climate. J. Meteorol. Res., 30, 283-297, doi: 10.1007/ s13351-016-6101-3. [Link]

Zhou, X., Y. Zhu, D. Hou, Y. Luo, J. Peng, and R. Wobus, 2017: Performance of the New NCEP Global Ensemble Forecast System in a parallel experiment. Weather Forecast., 32, 1989-2004, doi: 10.1175/wafd-17-0023.1. [Link] 